\title{
A LA BÚSQUEDA DEL "METODO ACCERTATO" DE UNA CIENCIA DE LOS SIGNOS DEL HOMBRE
}

\author{
Jürgen Trabant \\ (Universidad Libre de Berlín)
}

\begin{abstract}
RESUMEN: Este relato parte del magisterio de Eugenio Coseriu, de su vínculo con las tesis de Vico, y de cómo estas dirigieron el interés del autor hacia las "ciencias de la cultura" y en ese ámbito a la "ciencia de los signos" (semiología), para reconducirse por último al ámbito de la "semiótica" como ciencia comunicativa del signo humano. A partir de ahí, y siempre con Vico, se abre el nuevo camino de la "sematología" que -a diferencia de la semiología (estructural) y de la semiótica (comunicativa)- como una semiótica cognitiva tematiza el signo del hombre como la materialización del pensamiento.
\end{abstract}

Palabras Clave: Vico, $350^{\circ}$ Aniversario, W. Humboldt, E. Coseriu, semiología, semiótica, sematología, J. Trabant.

\section{In search for the "metodo accertato" of a science of the signs of man}

ABSTRACT: This story narrates a "journey" that starts from Eugenio Coseriu's teaching, from his link with Vico's thesis, and from how they directed the Author's interest towards the "sciences of culture" and, whithin that area, to the "science of signs" (semiology), to be finally reconducted to the field of "semiotics", as a communicative science of human sign. From there, and always with Vico, the new path of "sematology" dawns for the Author-one that, unlike (structural) semiology and (communicative) semiotics, thematizes the sign of man as the materialization of thought, as cognitive semiotics.

KeYwords: Vico, $350^{\text {th }}$ Anniversary, W. Humboldt, E. Coseriu, semiology, semiotics, sematology, J. Trabant.

\section{Alla ricerca del "metodo accertato" di una scienza dei segni dell'uomo}

RiASSUNTO: La presente ricostruzione prende le mosse dal magistero di Eugenio Coseriu, dal suo legame con le tesi di Vico, e da come queste orientarono l'interesse dell'Autore verso le "scienze della cultura" e, in quell'ambito, verso la "scienza dei segni" (semiologia), per approdare, infine, al campo della "semiotica" come scienza comunicativa del segno umano. Da lì, e sempre sulla scia di Vico, si apre il nuovo percorso della "sematologia" che -a differenza della semiologia (strutturale) e della semiotica (comunicativa)- in quanto semiotica cognitiva tematizza il segno dell'uomo in termini di materializzazione del pensiero.

PAROLE ChiaVe: Vico, $350^{\circ}$ Anniversario, W. Humboldt, E. Coseriu, semiologia, semiotica, sematologia, J. Trabant.

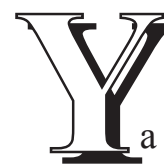

a no me acuerdo exactamente de cuándo fue, pero sí ciertamente de dónde: en Tubinga, donde estudiaba en los años Sesenta. Fue mientras acompañaba a mi venerado profesor Eugenio Coseriu de camino a clase, y conversábamos

Este artículo responde a una invitación expresa por parte de la Dirección de la Revista para este volumen especial por el $350^{\circ}$ Aniversario del nacimiento de G. Vico, habiendo superado los criterios de valoración y del proceso de aceptación. 
sobre las bases de nuestra disciplina. Yo quería saber hasta qué punto las ciencias de la cultura eran ciencias. "Las ciencias", que precisamente estaba estudiando en la Universidad como alumno de lenguas románicas, alemán y literatura, y que estaban bastante influenciadas por la hermenéutica y la interpretación y que, por lo tanto, a mí me parecían más unas experiencias subjetivas que ciencias objetivas. Coseriu me dijo que mi pregunta la podía responder el filósofo italiano Vico. Este precisamente dijo que el arte y el conocimiento que científicamente se obtienen de cualquier cosa es la práctica de llevarlo a efecto. Citó exactamente a Vico: «dunque il criterio di avere scienza di una cosa è il mandarla a effetto». Coseriu citó por tanto -como descubrí algo más tarde- una frase que aparece en un lugar bastante escondido de la segunda risposta a la crítica de De antiquissima (p. 258), en que fue formulado en italiano el principio verum-factum. Cuando verdaderamente hemos hecho algo es cuando podemos obtener la scienza, el auténtico conocimiento de las cosas y el objeto de la cultura, del mondo civile, y por lo tanto obtener la scienza de él. Este principio viquiano fue para mi maestro -y por lo tanto de aquí en adelante también para mí- el fundamento de la ciencia de la cultura. De todas formas, esto no me satisfacía plenamente. En la respuesta de mi maestro Coseriu-Vico faltaba algo. Me seguía preocupando la pregunta sobre la cientificidad de las humanities.

Inmediatamente me compré la Scienza nuova, traducida al alemán por Erich Auerbach, que se publicó en edición de bolsillo en 1966. Pero realmente no me ocupé del mismo libro hasta mucho más tarde (la edición italiana de bolsillo de Laterza la compré en 1978). Esta edición, en lugar de tener el interesante estudio introductorio de 1924 de Auerbach, presentaba uno que consideraba la Scienza nuova como "filosofía de la historia", y a mí realmente no me interesaba este aspecto nada en absoluto, pues lo que yo buscaba era algo sobre las bases teóricas de las ciencias de la cultura. De nuevo fue Eugenio Coseriu quien me alumbró el camino. En sus clases magistrales (1968/1971) sobre la historia de la filosofía del lenguaje le dedicó a Vico un largo y fundamental capítulo. Coseriu continuó con las investigaciones de Antonio Pagliaro, quien en los años cincuenta descubrió la filosofía del lenguaje de Vico. Desde luego hacía ya largo tiempo que Benedetto Croce había liberado a Vico de la cárcel de la filosofía de la historia, pero fue realmente Pagliaro el que abrió antes el otro capítulo de su filosofía del mondo civile, el capítulo de la filosofía del lenguaje, el capítulo homérico, y que Coseriu posteriormente continuó.

Mis propias investigaciones me condujeron en principio a un territorio aparentemente muy alejado de Vico: a la semiología de la literatura. Nosotros, jóvenes estructuralistas, intentábamos entonces aplicar a la literatura los principios estructurales inspirados en la nueva lingüística del Cours de Linguistique Générale. Esto era naturalmente un intento de responder a la pregunta viquiana sobre la cientificidad de las ciencias de la cultura. La lingüística estructuralista prometía que se podía intentar objetivar y cientifizar el objeto cultural. Estábamos entonces en el momen- 
to en el que las ciencias de la cultura perseguían una disciplina teórica y metódica más allá de la hermenéutica. Yo intenté transferir a la literatura la semiología altamente formal postsaussureana, la glosemática de Louis Hjelmslev. Esta versaba sobre unas estructuras inmanentes en el texto literario que se manifestaban objetivamente. Quizás este extraordinario juego intelectual verdaderamente poco pudo aportar a los estudios literarios. Pero a mí me condujo desde la literatura a otros objetivos culturales, dentro de la ciencia de los signos, y que entonces, siguiendo las propuestas saussureanas, se denominó "semiología".

En Italia, mientras trabajaba en la traducción al alemán de la obra de Umberto Eco Struttura assente, descubrí una semiótica que abandonaba terminológicamente a la "semiología" -y por lo tanto su referencia a la lingüística-. Este enfoque filosófico inspirado en Pierce me pareció más adecuado que el mío, es decir que la semiología de la lingüística saussuriana, y que abría un nuevo camino para una disciplina de la ciencia de la cultura. La "semiótica" de Eco se focaliza menos en las estructuras inmanentes del signo como comunicación que en el manejo de la semiótica. La expresión «semiosis» de Pierce comprendía, en lugar de los procesos estructurales del signo, programáticamente la procesualidad de los signos. Ese camino se consiguió a través de la semiótica: la semiótica fue por ello considerada como ciencia de la comunicación. Por ese motivo, los medios de comunicación, al menos en Alemania (revistas, $\mathrm{TV}$, cine) han aceptado la semiótica. La semiótica en su relación con la comunicación nos ofrece con esta nueva ciencia una ajustada teoría y un método. La dimensión cognitiva del signo está permanente e insuficientemente expuesta; es decir, la estudiamos durante el proceso de la abducción precisamente como un acontecimiento comunicativo, como una parte receptiva de la comunicación, como el procedimiento del entendimiento. El establecimiento de la semiótica como disciplina universitaria no fue posible en Alemania. Solo fue posible una semiotización de las ciencias de la comunicación. De todas formas, fundamos un par de revistas que estaban comprometidas con este camino y que aún hoy se publican. Desde la perspectiva de Vico intentamos dirigir el reconocimiento de su propio método, es decir, convertir la scienza de lo hecho por uno mismo en ciencia (con una terminología usual y un método científico). En este sentido, por aquel entonces, escribí un pequeño escrito sobre semiótica, en el que me esforcé de manera insistente y obsesiva en la disciplina metódica de la ciencia del signo humano. También mi libro Elementos de Semiótica (Elemente der Semiotik, 1976) está en la línea de la "comunicación": el "signo" es un acto por el que alguien le hace entender cualquier cosa a otra persona, y por lo tanto consigue una “intención comunicativa". Pero yo era profesor de ciencia del lenguaje, no de semiótica, y me ocupaba por tanto específicamente de la lengua, en vez del signo del hombre en sus múltiples variedades. Aunque de todas formas mis intereses lingüísticos giraban menos en torno a la gramática o al vocabulario que en torno al texto, es decir a la lengua en acción. Yo estaba profundamente unido a Coseriu en la «lingüística del 
hablar» ${ }^{1}$. Mi enfoque de la lengua como texto me llevó naturalmente también a Wilhelm von Humboldt, para quien la lengua es ante todo hablar, enérgeia, por lo que consideraba al lenguaje teóricamente ante todo como discurso.

Mas aunque no se puede entender a Humboldt solo como un teórico de la lengua viva, de todas formas tenemos que colocar esta básica afirmación en el contexto de sus posteriores perspectivas filosóficas de la lengua y de las lenguas: la experiencia fundamental de Humboldt fue su descubrimiento de las profundas diferencias entre las lenguas humanas, especialmente en su encuentro con el vascuence. Humboldt reconoce las bases de estas diferencias. Con ello pone de manifiesto que la lengua es ante todo la aproximación al mundo, "imagen del pensamiento" y que la diferencia de lenguas es lo mismo que la diferencia de pensamiento: las lenguas corresponden a distintas "visiones del mundo", no solo a distintos sonidos, como se pensaba en Europa desde Aristóteles. La ciencia del lenguaje es por tanto, y sobre todo, la ciencia del pensamiento humano. Humboldt reconocía naturalmente la ineludible presencia de lo comunicativo en el habla, entre el yo y el tú. Pero para Humboldt los fundamentos de los estudios de las lenguas en general conectan con Leibniz y Herder, precisamente supone el cambio hacia la apropiación cognitiva del mundo, hacia la idea de que la lengua es «materialización del pensamiento». La ciencia del lenguaje de Humboldt es en sentido enfático lingüística cognitiva. Se fundamenta expresamente en la crítica al signo y a la comunicación. Para Humboldt el enemigo de la ciencia del lenguaje es el signo y también el concepto tradicional de que la lengua sirve principalmente para la comunicación. El pensamiento lingüístico de Humboldt es explícitamente una anti-semiótica -va contra el signo y la comunicación-. Humboldt escribió convencido de que el concepto comunicativo-semiótico de la lengua «mata todo espíritu».

A saber, Humboldt enlaza con evidente pasión con el gran descubrimiento del nuevo pensamiento lingüístico europeo, es decir que la lengua es pensamiento. En confrontación con el mundo americano, en Europa se evidenció que las lenguas de los pueblos no europeos tenían distintas categorías, tanto semánticas como gramaticales, a las conocidas lenguas europeas. Ya no era posible pasar por alto que las lenguas son distintos sistemas cognitivos y no solo distintos sonidos comunicativos, ni de ningún modo que el pensamiento sea universal (europeo), sino que el pensamiento se forma desde las distintas lenguas, este hecho supuso un verdadero horror para el hombre europeo -comparable a lo que fue la pérdida de la idea del mundo como geocéntrico e incluso como eurocéntrico-.

Esto supuso tanto para Bacon como para Locke una catástrofe: el pensamiento de la lengua del pueblo, tanto popular como particular, viró hacia la universalidad de la ciencia. El pensamiento científico tiene por lo tanto que expulsar a estos "idola

1. N.T.- En español en el original.

2. N.T.- "Sprach-Wissenschaft". 
fori", a estos perversos y viejos ídolos del falso pensamiento y reformar la lengua. Aquí tienen su origen tanto los excesos lingüístico-políticos de la Revolución Francesa como la caza de brujas semántica en nombre de la corrección política. En cambio Leibniz reconoce el magnífico logro cognitivo de la lengua y transforma la queja de Locke sobre la diversidad de las lenguas precisamente en una loa a la diversidad de lenguas. Ve en las lenguas una enorme riqueza cognitiva, que hay que celebrar y cuidar. Esta revalorización hecha por Leibniz de la queja de Bacon-Locke es la base de la lingüística filosofía de la lengua de Humboldt o de la lingüística filosófica.

En este punto es cuando aparece realmente mi "auténtico" encuentro con Vico -y mi engarce con la Historia de la filosofía del lenguaje de Coseriu-. Desde Humboldt y del problema "lengua y pensamiento" en la filosofía de la Ilustración se llega "de manera natural" a Vico. De la misma manera que Humboldt responde a Kant, así Vico lo hace de forma filosófico-lingüística a Descartes. Vico realizó el primer linguistic turn de la filosofía europea (Humboldt el segundo, el actual es el tercero). Cien años antes de Humboldt, Vico ofreció una interesante respuesta a la pregunta de la filosofía europea sobre el papel cognitivo de la lengua (Vico no pudo conocer la filosofía del lenguaje de Leibniz; los nouveaux essais se publicaron en 1765, veinte años después de su muerte). Humboldt integra la lengua en la teoría del conocimiento de Kant (que no tiene en cuenta el lenguaje): la lengua es el órgano que da forma al pensamiento, es la fuerza de la imaginación que crea el pensamiento y que se materializa en las distintas lenguas de los hombres. Vico opina lo contrario a la filosofía de la teoría del conocimiento cartesiana: el hombre educa su pensamiento a partir de las fuerzas cognitivas de su cuerpo.

La corpolentissima fantasia crea el pensamiento en caracteres poéticos, y en materializaciones de las fuerzas espirituales tanto visuales como auditivas. Pero para Vico el pensamiento no se materializa solo en lenguaje oral, sino también en muchísimos otros signos visuales: imágenes, gestos, dibujos, figuras míticas. El idioma es uno de los gemelos de la semiótica, aquella que crea el lógos poético: «nacquero esse gemelle le lettere con le lingue» $(S N 44, \S 33)$. Cuando Vico reflexiona sobre el idioma, en cuanto que lo considera gemelo a distintas y variadas encarnaciones del pensamiento, es lo que me retrotrae a mis inicios semióticos: a los signos del hombre. Pero tanto la filosofía del lenguaje de Humboldt, como también la filosofía de los caracteres poéticos de Vico conduce a una nueva perspectiva de esta semiótica. En esta ocasión no se orienta a las propiedades estructurales del signo, ni tampoco se interroga teóricamente sobre las intenciones comunicativas, sino que tematiza el signo del hombre como la materialización del pensamiento. Es pues la perspectiva de una semiótica cognitiva. Yo la nombro (sèmata) sematología con la expresión griega precisamente para diferenciarla de la semiología (estructural) y de la semiótica (comunicativa).

Vico siempre ha sido un punto de encuentro para el contexto investigador, y yo he tenido la suerte de haber pertenecido a un grupo de investigación que en los 
últimos años ha trabajado sobre la relación entre la imagen y la lengua y que, por tanto, refleja las últimas investigaciones sobre el embodiment del pensamiento humano. En este contexto siempre ha estado presente tanto el nacimiento de los gemelos poéticos de Vico, lengua e imagen - «nacquero esse gemelle»-, como también su filosofía de la fantasía y del ingenio en la batalla anticartesiana. Mi pensamiento ha regresado con Vico a puerto, al «desiderato porto di questa scienza» $(S N 30, \S 122)$. Y este puerto es la gran discoverta de Vico, aún más que el axiomaVico que fue el que me guió al inicio de mi viaje; esta gran discoverta es la que explica que los hombres son poetas y que sus pensamientos se expresan en caracteres poéticos: «furon Poeti; i quali parlarono per Caratteri Poetici» $(S N 44, \S 34)$.

Y con ello Vico definitivamente sigue presente en la respuesta a mi pregunta sobre la cientificidad de las ciencias de la cultura. La primera respuesta que Vico ofrece, refuerza la base de las humanities: podemos tener el verdadero conocimiento, scien$z a$, de nuestro mundo cultural precisamente porque hemos sido nosotros los que lo hemos hecho, por lo tanto del «mondo civile, del quale, perché l'avevano fatto gli uomini, ne potevano conseguire la scienza gli uomini» (SN44, § 331). Posteriormente me ocupé de la búsqueda de una cientificidad de la filología y pensé encontrarla en las proposiciones de la lingüística estructural, es decir a través de procesos científicos y objetivos, lo que Vico ya había nombrado en la ejecución del método como la segunda condición para la cientificidad: las reglas de las ciencias de la naturaleza permanecen eficaces. También en la nueva ciencia sigue el viejo principio aristotélico «scientia debet esse de universalibus et aeternis». En esta búsqueda de unas leyes generales Vico sigue el método de Lord Verulam, es decir el método empírico de Bacon de la inducción de las verdades generales (universalia et aeterna) a partir de un método empírico: «il metodo di filosofare più accertato» (SN44, § 163). Sin embargo, las ciencias modernas de la cultura no pueden seguir en su totalidad a Vico con estas directrices metodológicas. En las ciencias sociales (que pertenecen a las ciencias del mondo civile) quizás sea posible encontrar perspectivas generales (quizás no para siempre). En relación con las obras de arte, los textos literarios o los acontecimientos históricos comprenderemos precisamente lo único y especial como único y especial. Pero de ello Vico no dice nada. Para el reconocimiento de lo hecho por uno mismo Vico propone que sigamos el método científico. Algunos intérpretes viquianos lo han entendido de tal modo que lo consideran como las reglas de la hermenéutica. Pero realmente esto no lo ha dicho Vico -y por tanto tampoco ha formulado dicha regla-. Pero desde luego una hermenéutica científica postviquiana podría ciertamente ser una respuesta probable a la búsqueda de Vico de un método seguro, «metodo accertato di filosofare». Aunque también tienen aquí su legítimo lugar otros métodos estructurales o de otro tipo.

[Traducción del alemán por Pablo Badillo O’Farrell]

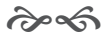

